\title{
REGIONAL SPILLOVER EFFECT TERHADAP PERTUMBUHAN EKONOMI KOTA PEKANBARU
}

\section{REGIONAL SPILLOVER EFFECT ON ECONOMIC GROWTH IN PEKANBARU CITY}

\author{
M. Irfan Rosyadi ${ }^{1}$, Sinta Yulyanti ${ }^{2}$ \\ Universitas Islam Riau ${ }^{1,2}$ \\ m.irfanrosyadi@eco.uir.ac.id ${ }^{1}$
}

\begin{abstract}
The spillover effect of economic activity from one area to another is due to the intersector linkages, which have implications for economic growth. This study examines and presents empirical evidence on the effects of economic growth in the districts of Siak, Pelalawan, Kampar, Kuantan singingi, and Bengkalis, which have spatial impacts on the economic growth of Pekanbaru City. Through quantitative methods with secondary data from the Regency / City Central Statistics Agency in Riau Province, the data used is the Gross Regional Domestic Product from 2010 to 2019, then analyzed using the Multiple regression method. The study results show that Kampar, Kuantan singingi, Pelalawan, and Siak districts have a significant effect on the economic growth of Pekanbaru City, while Bengkalis does not affect. Not all of the natural resources owned by each district can provide a spillover effect of growth. However, a dominant sector in absorbing labor will provide a spillover effect of economic growth from one region to another.
\end{abstract}

Keyword: Regional Spillover Effect. Economic Growht, Multiple Regression. Pekanbaru

\begin{abstract}
ABSTRAK
Limpahan aktifitas ekonomi suatu daerah terhadap daerah lain disebabkan adanya keterkaitan antar sektor yang berimplikasi pada pertumbuhan ekonomi. Studi ini mengkaji dan menyajikan bukti empiris tentang pengaruh dari pertumbuhan ekonomi Kabupaten Siak, Pelalawan, Kampar, Kuantan singing dan Bengkalis yang memberikan dampak spasial bagi pertumbuhan ekonomi Kota Pekanbaru. Melalui metode kuantitatif dengan data sekunder dari Badan Pusat Statistik Kabupaten/Kota di Provinsi Riau, data yang digunakan yaitu Produk Domestik Regional Bruto dari tahun 2010 sampai 2019, selanjutnya dianalisa menggunakan metode Multiple regression. Hasil studi menunjukkan bahwa Kabupaten Kampar, Kuantan singingi, Pelalawan dan Siak berpengaruh signifikan terhadap pertumbuhan ekonomi Kota Pekanbaru, sementara Kabupaten Bengkalis tidak berpengaruh. Sumberdaya alam yang dimiliki setiap kabupaten tidak seluruhnya dapat memberikan limpahan pertumbuhan, namun sektor yang dominan menyerap tenaga kerja akan memberikan limpahan pertumbuhan ekonomi suatu daerah terhadap daerah lainnya.
\end{abstract}

Kata Kunci: Efek Limpahan Regional. Pertumbuhan Ekonomi, Regresi Berganda. Pekanbaru 


\section{PENDAHULUAN}

Pembangunan pada hakekatnya merupakan upaya terencana dan terprogram yang dilakukan secara terus menerus untuk menciptakan masyarakat yang lebih baik. Pembangunan daerah sebagai bagian integral dari pembangunan nasional mempunyai arti yang sangat penting dalam rangka mewujudkan tujuan nasional. Pembangunan ekonomi daerah merupakan suatu proses dimana pemerintah daerah dan masyarakat mengelola sumberdaya yang ada dan membentuk suatu pola kemitraan untuk menciptakan suatu lapangan kerja baru dan merangsang perkembangan kegiatan ekonomi (Arsyad, 2004).

Dalam teori Linkage Effect dan Industrial Effect, pertumbuhan ekonomi suatu daerah akan memberikan efek yang menguntungkan dan efek yang merugikan bagi daerah lain (Hirschman, 1984). Salah satu efek yang menguntungkan bagi daerah lain misalnya Industrial Effect yang dapat meningkatkan pertumbuhan ekonomi secara agregat, karena aktifitas industri suatu daerah dapat membantu penyerapan tenaga kerja dan meningkatkan pendapatan perkapita. Regional spillover effect pertumbuhan ekonomi suatu daerah dapat memberikan limpahan pertumbuhan terhadap daerah lainnya.

Pembangunan ekonomi suatu daerah tak lepas dari pengaruh daerah lain yang memiliki potensi sumberdaya serta memiliki kedekatan secara administratif. Kota Pekanbaru merupakan ibu Kota Provinsi Riau yang berdekatan dengan beberapa Kabupaten antara lain; Kabupaten Kampar, Kabupaten Siak, Kabupaten Pelalawan, Kabupaten Kuansing dan Kabupaten Bengkalis. Kabupaten tersebut memiliki potensi ekonomi yang berbeda, dengan potensi sumberdaya yang dimiliki setiap daerah yang bersinambungan dalam meningkatkan pertumbuhan ekonomi secara berkelanjutan.

Hal ini menjadi dorongan setiap daerah untuk melakukan kerjasama (cross border spatial cooperation) agar dapat saling memberikan limpahan aktifitas ekonomi.

Fluktuasi pertumbuhan ekonomi Kota Pekanbaru tidak lepas dari kondisi pertumbuhan ekonomi Kabupaten disekitarnya. Penurunan aktifitas perekonomian di Kabupaten yang berdekatan dengan Kota Pekanbaru secara umum dapat mencerminkan kondisi perekonomian Kota Pekanbaru, karena distribusi barang serta sentra perdagangan di Provinsi Riau berada di KotaPekanbaru.

Tabel 1. Produk Domestik Regional Bruto Atas Dasar Harga Konstan dan Laju Pertumbuhan Ekonomi Kota Pekanbaru tahun 2010-2019

\begin{tabular}{ccc}
\hline Tahun & $\begin{array}{c}\text { Produk Domestik Regional Bruto Atas Dasar } \\
\text { Harga Konstan 2010 (Milyar Rp) }\end{array}$ & $\begin{array}{c}\text { Laju pertumbuhan ekonomi } \\
\text { (Persen) }\end{array}$ \\
\hline $\mathbf{2 0 1 0}$ & $41.702,83$ & - \\
\hline $\mathbf{2 0 1 1}$ & $44.845,77$ & 7,54 \\
\hline $\mathbf{2 0 1 2}$ & $48.351,74$ & 7,82 \\
\hline $\mathbf{2 0 1 3}$ & $51.053,17$ & 5,59 \\
\hline $\mathbf{2 0 1 4}$ & $54.575,48$ & 6,90 \\
\hline $\mathbf{2 0 1 5}$ & $57.616,75$ & 5,57 \\
\hline $\mathbf{2 0 1 6}$ & $60.891,07$ & 5,68 \\
\hline $\mathbf{2 0 1 7}$ & $64.619,26$ & 6,12 \\
\hline $\mathbf{2 0 1 8}$ & $68.108,76$ & 4,40 \\
\hline $\mathbf{2 0 1 9}$ & $72.200,41$ & 5,61 \\
\hline
\end{tabular}

Sumber: Badan Pusat Statistik Provinsi Riau (2020) 
Pertumbuhan ekonomi diukur berdasarkan Produk Domestik Regional Bruto (PDRB) setiap tahunnya. Peningkatan PDRB di Kota Pekanbaru dari tahun 2010-2019 disebabkan oleh dorongan aktifitas ekonomi dari sektor perdagangan, industri pengolahan dan manufaktur. Peningkatan PDRB tersebut tidak sepenuhnya peran dari aktifitas ekonomi yang terdapat di Kota Pekanbaru, dampak aktifitas ekonomi daerah lainnya juga memberikan sumbangsih terhadap pertumbuhan ekonomi di Kota Pekanbaru.

Regional Spillover dari daerah lainnya dapat berdampak positif maupun negative. Perlu kebijakan yang tepat untuk merespon dampak dari pertumbuhan ekonomi tersebut. Pemerintah berperan penting dalam merespon melalui kebijakan pembangunan yang tepat karena pertumbuhan ekonomi daerah menjadi acuan atas kinerja pemerintah daerah dalam mengelola daerahnya.

Studi tentang regional spillover effect menjadi topik pembahasan dalam lingkup ekonomi regional yang mengacu pada aktifitas ekonomi setiap daerah yang memberikan efek terhadap daerah sekitarnya. Kerjasama antar daerah dalam melakukan aktifitas ekonomi yang saling berkaitan satu sama lain untuk mendongkrak pertumbuhan ekonomi. Regional spillover bagi pertumbuhan daerah sangat penting. Regional spillover tersebut meliputi Knowledge Spillover, Industri Spillover dan Growth Spillover (Capello, 2009).

Wibisono dan Kuncoro (2015); Suparta (2009); Carlino (2001); (Harahap et al., 2015); (Luo, 2005); Jaffe, Trajtenberg, dan Fogarty (2000); Aghion dan Jaravel (2015); Li and Li (2018); MAhmed (2012); Anata Salam dan Prishardoyo (2018); Seif et al., (2017); Aiyubbi \& Wijayanti, (2014); Laksono et al., (2018) telah melakukan kajian mengenai spillover effect dengan metode dan objek yang berbeda-beda. Hal ini mengindikasikan bahwa kajian mengenai spillover effect telah banyak dilakukan oleh peneliti di berbagai Negara dan daerah.

Berdasarkan pemaparan diatas perlu kiranya melakukan kajian empiris tentang Regional Spillover Effect terhadap Kota Pekanbaru, karena sejauh ini belum ada kajian khusus dilakukan baik oleh peneliti atau lembaga kajian dari pemerintah, hal ini dibuktikan dengan tidak ditemukannya kajian regional spillover effect dari sumber lainnya. Penelitian terkait Limpahan aktifitas ekonomi dari Kota Pekanbaru penting untuk dilakukan agar dapat diketahui seberapa besar pengaruh dari aktifitas perekonomian daerah sekitar yang memberikan limpahan aktifitas ekonomi sehingga pertumbuhan ekonomi kota Pekanbaru terus terjadi peningkatan.

\section{METODE PENELITIAN}

Penelitian ini menggunakan metode kuantitatif dengan data skunder yang diperoleh dari Badan Pusat Statistik (BPS) Provinsi Riau. Data yang digunakan untuk analisa yaitu data Produk Domestik Regional Bruto (PDRB) dan Laju pertumbuhan ekonomi Atas Dasar Harga Konstan (ADHK) dari tahun 2010 sampai tahun 2019. Daerah yang digunakan sebagai objek penelitian yaitu Kota Pekanbaru, Kabupaten Siak, Kabupaten Bengkalis, Kabupaten Kampar, Kabupaten Kuansing dan Kabupaten Pelalawan.

Penelitian ini menggunakan metode regresi linier berganda (Multiple linear regression) yang merupakan metode yang melibatkan lebih dari satu variabel independen. Dalam hal ini variabel dependen yang digunakan yaitu PDRB Kota Pekanbaru, sementara variabel independennya yaitu PDRB 
Kabupaten Siak, PDRB Kabupaten Bengkalis, PDRB Kabupaten Kampar, PDRB Kabupaten Kuansing dan PDRB Kabupaten Pelalawan. Terdapat beberapa tahapan dalam metode regresi linier berganda yaitu:

Tahapan Pertama yaitu

Pengujian Asumsi klasik digunakan untuk mendeteksi apakah model estimasi dari metode regresi linier berganda (Multiple linear regression) memenuhi asumsi Ordinary least square (OLS), berikut asumsi yang digunakan (Widarjono, 2018):

1. Uji normalitas merupakan pengujian untuk mengetahui bahwa model yang digunakan sesuai dengan asumsi dari model regresi linier berganda yaitu berdustribusi normal. Dalam mengambil keputusan yang ditentukan melalui Probability Jerque-Bera, jika probability JerqueBera lebih besar dari alpha 5 persen maka data tidak berdistribusi normal. Sebaliknya jika probability JerqueBera lebih kecil dari alpha 5 persen maka data berdistribusi normal.

2. Uji heteroskedastisitas merupakan asumsi yang digunakan untuk megetahui ada tidaknya variabel gangguan yang tidak konstan dalam model yang digunakan. Metode yang digunakan untuk mendeteksi heteroskedastisitas, salah satunya yaitu Uji White, dengan ketentuan Jika nilai probabilitas Chi squares lebih besar dari alpha 5 Persen maka tidak terjadi masalah heteroskedastisitas, begitu sebaliknya jika nilai probabilitas Chi squares lebih kecil dari alpha 5 Persen maka terjadi masalah heteroskedastisitas.

3. Uji autokorelasi merupakan asumsi untuk melihat ada tidaknya hubungan variabel gangguan antar satu observasi dengan observasi lainnya. Untuk mendeteksi ada tidaknya autokorelasi dalam model dapat dilakukan dengan metode yang dikembangkan oleh Breusch dan Godfrey yang dikenal dengan uji Langrange Multiplier. Penentuan ada tidaknya masalah autokorelasi dapat dilihat dari nilai probabilitasnya, jika lebih besar dari alpha 5 persen maka tidak terdapat autokorelasi. Sebaliknya jika lebih kecil dari alpha 5 persen maka terdapat autokorelasi.

4. Uji multikolinieritas digunakan untuk mengetahui ada tidaknya hubungan linier antar variabel independen dalam suatu regresi. Metode yang dapat digunakan untuk menguji ada tidaknya masalah multikolinearitas pada suatu model regresi dengan cara menguji korelasi parsial antar variabel independen. Ketentuannya yaitu jika koefisien korelasi cukup tinggi diatas 0.85 Maka model mengandung unsur multikolinieritas, dan jika sebaliknya maka tidak ada korelasi antar variabel independen.

Tahapan kedua dalam analisis data menggunakan metode Regresi linier berganda (Multiple linear regression) dengan menggunakan data times series. Regresi linier berganda merupakan model regresi linier yang memiliki lebih dari satu variabel independen atau dependen. Berikut persamaan estimasi yang digunakan untuk mengetahui nilai dari variabel independen (X) yang mempengaruhi variabel dependen $(\mathrm{Y})$.

$$
\begin{array}{r}
Y_{t}=\beta_{0}+\beta_{1} X_{1 t}+\beta_{2} X_{2 t}+\beta_{3} X_{3 t} \\
+\beta_{4} X_{4 t}+\beta_{5} X_{5 t}+e_{t}
\end{array}
$$

Keterangan:

$Y$ : PDRB Kota Pekanbaru

$X_{1}$ : PDRB Kabupaten Bengkalis

$X_{2}$ : PDRB Kabupaten Kuansing

$X_{3}$ : PDRB Kabupaten Pelalawan

$X_{4}$ : PDRB Kabupaten Siak

$X_{5}$ : PDRB Kabupaten Kampar

$e:$ Standar error

$t$ : Time

$\beta_{0}$ : Intersep 
$\beta_{1}, \beta_{2}, \beta_{3}, \beta_{4}, \beta_{5}: \quad$ Koefisien regresi parsial

Model Regresi berganda diuji dengan beberapa pengujian yaitu: Uji tstatistik (Pengujian variabel secara individu). Uji f-statistik (Uji hipotesis Koefisien Regresi secara menyeluruh) dan Koefisien Determinasi (R-Square) (Widarjono, 2018).

\section{HASIL DAN PEMBAHASAN Hasil Asumsi Klasik}

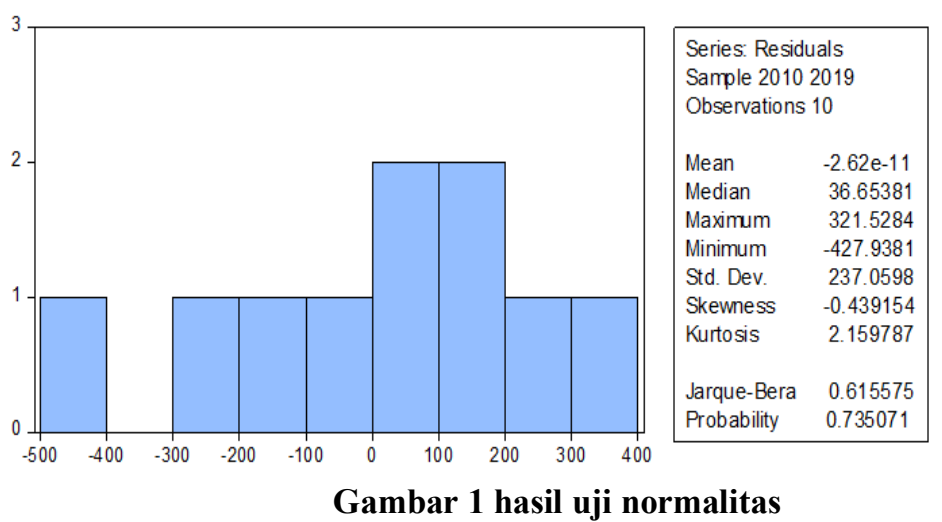

Sumber: Hasil olahan menggunakan Eviews 10 (2020)
Pengujian asumsi klasik digunakan agar model memenuhi asumsi Ordinary least square (OLS). Berikut hasil uji asumsi klasik:

\section{Uji Normalitas}

Hasil uji normalitas menunjukkan bahwa data dalam model berdistribusi normal, karena probability Jerque-Bera bernilai 0.735071 artinya lebih besar dari alpha 5 persen.

\section{Uji Autokorelasi}

Dari hasil uji Langrange Multiplier pada tabel dibawah ini, dihasilkan nilai Obs*R-Squared sebesar 2.730543 dengan nilai probabilitas Chi-
Square 0.2553 atau 25,53 persen. maka dapat diketahui dalam model tidak terdapat masalah autokorelasi karena nilai probabilitas Chi-Square lebih besar dari alpha 5 persen.

Tabel 2 Uji Autokorelasi

\begin{tabular}{lcll}
\hline Breusch-Godfrey Serial Correlation LM Test: & & \\
\hline F-statistic & 0.375619 & Prob. F(2,2) & 0.7269 \\
Obs*R-squared & 2.730543 & Prob. Chi-Square(2) & 0.2553 \\
\hline
\end{tabular}

Sumber: Hasil olahan menggunakan Eviews 10 (2020)

\section{Uji Heterokedastisitas}

Berdasarkan tabel dibawah diperoleh nilai Obs*R-squared 6.777 dan probabilitas Chi-Squares 0.2377 atau
23,77 persen, artinya tidak terdapat masalah heteroksedastisitas dalam model, karena nilai probabilitas ChiSquare lebih besar dari alpha 5 persen.

Tabel 3 Hasil Uji Heterokedastisitas

\begin{tabular}{llll}
\hline \multicolumn{4}{l}{ Heteroskedasticity Test: White } \\
\hline F-statistic & 1.682753 & Prob. F(5,4) & 0.3171 \\
Obs*R-squared & 6.777770 & Prob. Chi-Square(5) & 0.2377 \\
Scaled explained SS & 0.628862 & Prob. Chi-Square(5) & 0.9866 \\
\hline
\end{tabular}

Sumber: Hasil olahan menggunakan Eviews 10 (2020) 
Uji Multikolinieritas

Bedasarkan hasil uji multikolinieritas ditemukan masalah multikolinieritas karena terdapat korelasi antar variabel independen dengan nilai diatas 0.85 . berdasarkan ahli ekonometrika yaitu Gujarati, (2003); Ghozali \& Ratmono, (2017); Widarjono, (2018) sependapat bahwa jika dalam model mengandung masalah multikolinearitas maka dapat diatasi dengan cara tanpa perbaikan dan dengan perbaikan. Karena yang kita analisa adalah pertumbuhan ekonomi, maka wajar jika terdapat korelasi antar variabel bebas, yaitu PDRB antar Kabupaten yang menjadi variabel independen. Oleh karena itu masalah multikolinieritas pada studi ini memilih solusi tanpa perbaikan.

\section{Hasil regresi berganda}

Setelah model memenuhi asumsi yang disyaratkan pada metode Ordinary lest square. Lanjut tahapan berikutnya yaitu regresi linier berganda dengan beberapa pengujian untuk memperoleh hasil yang dapat di analisa. Berikut hasil regresi linier berganda:

\section{Uji t-statistik}

Uji t-statistik merupakan suatu pengujian untuk melihat apakah variabel independen secara individu mempengaruhi variabel dependen. Dalam pengujian dengan metode secara umum untuk melihat pengaruhnya melalui nilai t-statistik, dengan menggunakan nilai t-statistik akan diperoleh nilai yang dapat menjawab hipotesis apakah Ho ditolak atau diterima. Berikut Kriteria pengujian hipotesis:

1. Jika nilai probabilitas t-statistik lebih besar dari 5 persen, maka Ho diterima, artinya variabel bebas tidak mempengaruhi variabel terikat secara signifikan.

2. Jika nilai probabilitas t-statistik kecil dari 5 persen, maka Ho ditolak, artinya variabel bebas mempengaruhi variabel terikat secara signifikan.

Untuk menentukan keputusan dari hipotesis, dapat dilihat dari nilai probabilitas ( $\mathrm{p}$-value). Jika nilai probabilitas (p-value) lebih kecil dari nilai alpha 5 persen maka menolak Ho, artinya variabel independen mempengaruhi variabel dependen secara signifikan. Berikut hasil uji t-statistik variabel independen terhadap variabel dependen. Berikut hasil pengujian Tstatistik:

Tabel 4 Hasil Uji t-statistik

\begin{tabular}{lllll}
\hline Variabel & Coefficient & t-Statistic & Probabilitas & Keterangan \\
\hline $\mathrm{X}_{1}$ (PDRB Bengkalis) & -0.06 & -1.31 & 0.25 & Tidak Signifikan \\
\hline $\mathrm{X}_{2}$ (PDRB Kuantansingingi) & -1.78 & -3.03 & 0.03 & Signifikan* \\
\hline $\mathrm{X}_{3}$ (PDRB Pelalawan) & 3.05 & 8.71 & 0.00 & Signifikan* \\
\hline $\mathrm{X}_{4}$ (PDRB Siak) & 1.49 & 5.72 & 0.00 & Signifikan* \\
\hline $\mathrm{X}_{5}$ (PDRB Kampar) & 0.61 & 2.14 & 0.09 & Signifikan** \\
\hline
\end{tabular}

Sumber: Hasil olahan menggunakan Eviews 10 (2020)

*Significant on $\alpha=0,05$

$* *$ Significant on $\alpha=0,10$

1. Hasil pengujian PDRB Bengkalis terhadap PDRB Kota Pekanbaru. Dari hasil pengujian diperoleh nilai tstatistik yaitu -1.317218 dengan nilai probabilitas lebih besar dari 5 persen yaitu 0.2582. Artinya menerima Ho, karena variabel PDRB Bengkalis tidak signifikan mempengaruhi PDRB Pekanbaru. 
2. Hasil pengujian PDRB Kampar terhadap PDRB Kota Pekanbaru. Dari hasil pengujian diperoleh nilai tstatistik yaitu 2.145298 dengan nilai probabilitas tidak signifikan pada alpha 5 persen namun signifikan jika menggunakan alpha 10 persen dengan nilai probabilitas 0.0985 atau 9,8 persen. Maka dapat diartikan PDRB Kampar secara signifikan mempengaruhi PDRB Pekanbaru.

3. Hasil pengujian PDRB Kuantan singing terhadap PDRB Kota Pekanbaru. Dari hasil pengujian diperoleh nilai t-statistik yaitu 3.030161 dengan nilai probabilitas lebih besar dari 5 persen yaitu 0.0388 . Artinya menolak Ho, karena variabel PDRB Kuantan singing secara signifikan mempengaruhi PDRB Pekanbaru.

4. Hasil pengujian PDRB Pelalawan terhadap PDRB Kota Pekanbaru. Dari hasil pengujian diperoleh nilai tstatistik yaitu 8.713168 dengan nilai probabilitas lebih kecil dari 5 persen yaitu 0.0010. Artinya menolak Ho, karena variabel PDRB Pelalawan signifikan mempengaruhi PDRB Pekanbaru.

5. Hasil pengujian PDRB Siak terhadap PDRB Kota Pekanbaru. Dari hasil pengujian diperoleh nilai t-statistik yaitu 5.728944 dengan nilai probabilitas lebih besar dari 5 persen yaitu 0.0046. Artinya menolak Ho, karena variabel PDRB Siak secara signifikan mempengaruhi PDRB Pekanbaru.

\section{Uji f-statistik}

Nilai statistik Uji f-statistik merupakan suatu uji untuk mengetahui apakah variabel independen secara bersama-sama mempengaruhi variabel dependen. Hasil pengujian menunjukkan bahwa nilai Hasil Uji f sebesar 1457.795 dengan tingkat probabilitas dibawah alpha 5 persen yaitu 0.000001 . Berarti variabel independen bersama-sama mempengaruhi variabel dependen sebesar 1457.795 dengan tingkat signifikansi 0.000001 .

\section{Koefisien Determinasi $\left(\mathbf{R}^{2}\right)$}

Koefisien determinasi (Rsquared) adalah nilai yang menunjukkan seberapa besar variasi variabel dependen dapat dijelaskan oleh variabel-variabel independen. Pada model estimasi regresi berganda diperoleh nilai koefisien determinasi sebesar 0.999452 sehingga variasi dari variabel dependen dapat dijelaskan oleh variabel independen sebesar 99, 94 persen.

\section{Regional Spillover Effect}

Selain menjadi ibu Kota Provinsi Riau, Kota Pekanbaru berada dilokasi strategis yang diapit oleh beberapa kabupaten yang memiliki sumberdaya alam potensial. Sektor unggulan Kota Pekanbaru yaitu sektor perdagangan, Kontruksi dan industri pengolahan. Berikut sektor unggulan penyumbang PDRB Kota Pekanbaru. 
Tabel 5. Distribusi PDRB Kota Pekanbaru menurut Sektor tahun 2010-2019 (Persen)

\begin{tabular}{ccccc}
\hline Tahun & Kontruksi & $\begin{array}{c}\text { Perdagangan besar dan eceran; reparasi } \\
\text { mobil dan sepeda motor }\end{array}$ & $\begin{array}{c}\text { Industri } \\
\text { Pengolahan }\end{array}$ & $\begin{array}{c}\text { Sektor } \\
\text { lainnya }\end{array}$ \\
\hline $\mathbf{2 0 1 0}$ & 28,45 & 28,45 & 20,86 & 22,24 \\
\hline $\mathbf{2 0 1 1}$ & 29,02 & 28,51 & 20,92 & 21,55 \\
\hline $\mathbf{2 0 1 2}$ & 28,80 & 28,85 & 20,60 & 21,75 \\
\hline $\mathbf{2 0 1 3}$ & 29,58 & 28,32 & 20,29 & 21,81 \\
\hline $\mathbf{2 0 1 4}$ & 29,98 & 30,01 & 18,98 & 21,03 \\
\hline $\mathbf{2 0 1 5}$ & 29,60 & 29,31 & 19,97 & 21,12 \\
\hline $\mathbf{2 0 1 6}$ & 29,51 & 29,68 & 19,99 & 20,82 \\
\hline $\mathbf{2 0 1 7}$ & 29,66 & 30,47 & 19,88 & 19,99 \\
\hline $\mathbf{2 0 1 8}$ & 30,21 & 30,40 & 19,63 & 19,76 \\
\hline $\mathbf{2 0 1 9}$ & 30,16 & 31,41 & 19,24 & 19,19 \\
\hline
\end{tabular}

Sumber: Badan Pusat Statistik Kota Pekanbaru (2020)

Aktifitas perekonomian di kabupaten sekitar Kota Pekanbaru membuka peluang untuk menyediakan barang dan jasa yang dibutuhkan atau menjadikan Kota Pekanbaru sebagai penerima limpahan aktifitas ekonomi. Menurut Capello (2009) pertumbuhan ekonomi suatu daerah akan dapat meningkatkan pendapatan daerah tersebut, yang berakibat pada peningkatan permintaan barang dan jasa. Permintaan yang terus meningkat menyebabkan barang dan jasa harus di impor dari luar daerah.

Kabupaten disekitar Kota Pekanbaru tidak semuanya memberikan efek positif, dampak negative juga dapat ditimbulkan. Seperti kabupaten Bengkalis dan kabupaten kuantan singing. Sementara itu, kabupaten siak, kabupaten Kampar dan kabupaten pelalawan menunjukkan efek positif terhadap pertumbuhan ekonomi Kota Pekanbaru. Fluktuasi pertumbuhan ekonomi di Kabupaten/Kota menjadi salah satu factor penentu yang mempengaruhi efek yang ditimbulkan seperti pertumbuhan ekonomi kabupaten bengkalis yang terus terjadi penurunan dari tahun 2012 sampai tahun 2019. Berikut laju pertumbuhan ekonomi di Kabupaten/Kota tersebut.

Tabel 6. Laju Pertumbuhan Ekonomi Enam Kabupaten/kota di Provinsi Riau Tahun 2011-2019 (Persen)

\begin{tabular}{ccccccc}
\hline Tahun & Pekanbaru & Kampar & Siak & Bengkalis & Pelalawan & Kuantan singingi \\
\hline $\mathbf{2 0 1 1}$ & 7,5 & 4,1 & $-0,5$ & 7,9 & 5,7 & 4,17 \\
\hline $\mathbf{2 0 1 2}$ & 7,8 & 5,8 & 2,1 & $-0,7$ & 3,0 & 5,93 \\
\hline $\mathbf{2 0 1 3}$ & 5,6 & 6,3 & $-2,3$ & $-3,3$ & 5,6 & 5,47 \\
\hline $\mathbf{2 0 1 4}$ & 6,9 & 3,4 & $-1,0$ & $-3,9$ & 6,2 & 5,14 \\
\hline $\mathbf{2 0 1 5}$ & 5,6 & 1,1 & $-0,2$ & $-2,7$ & 2,5 & $-2,14$ \\
\hline $\mathbf{2 0 1 6}$ & 5,7 & 2,8 & 0,4 & $-2,5$ & 3,0 & 3,89 \\
\hline $\mathbf{2 0 1 7}$ & 6,1 & 3,0 & 0,9 & $-1,7$ & 4,1 & 4,37 \\
\hline $\mathbf{2 0 1 8}$ & 4,4 & 1,9 & 1,1 & $-1,7$ & 3,8 & 4,68 \\
\hline $\mathbf{2 0 1 9}$ & 5,6 & 3,9 & 1,5 & $-1,9$ & 3,9 & 4,62 \\
\hline
\end{tabular}

Sumber: Badan Pusat Statistik Provinsi Riau (2020)

\section{Pertumbuhan Ekonomi Kabupaten Bengkalis terhadap Kota Pekanbaru}

Dampak negative dan tidak signifikan pada pertumbuhan ekonomi Kabupaten Bengkalis terhadap pertumbuhan ekonomi Kota Pekanbaru salah satunya disebabkan oleh kondisi geografis kabupaten bengkalis yang tidak berbatasan langsung dengan Kota Pekanbaru, meskipun kabupaten 
bengkalis memiliki PDRB terbesar di provinsi riau. Sehingga sektor pertambangan dan penggalian yang menjadi sektor unggulan di kabupaten Bengkalis tidak mampu memberikan limpahan aktifitas ekonomi terhadap Kota Pekanbaru. Hal ini terjadi karena hasil dari sektor pertambangan yang mulai menurun dan di ikuti penurunan PDRB di kabupaten bengkalis secara agregat. Rata-rata sektor pertambangan menyumbang 70 persen terhadap PDRB Kabupaten Bengkalis dari tahun 20102019.

Tabel 7 Sektor Pertambangan dan Penggalian Kabupaten Bengkalis tahun 2010-2019 (Persen)

\begin{tabular}{ccc}
\hline Tahun & Pertambangan dan Penggalian & Sektor lainnya \\
\hline $\mathbf{2 0 1 0}$ & 75,98 & 24,02 \\
\hline $\mathbf{2 0 1 1}$ & 81,47 & 18,53 \\
\hline $\mathbf{2 0 1 2}$ & 82,33 & 17,67 \\
\hline $\mathbf{2 0 1 3}$ & 82,36 & 17,64 \\
\hline $\mathbf{2 0 1 4}$ & 80,22 & 19,78 \\
\hline $\mathbf{2 0 1 5}$ & 73,15 & 26,85 \\
\hline $\mathbf{2 0 1 6}$ & 89,56 & 10,44 \\
\hline $\mathbf{2 0 1 7}$ & 66,73 & 33,27 \\
\hline $\mathbf{2 0 1 8}$ & 68,90 & 31,10 \\
\hline $\mathbf{2 0 1 9}$ & 65,15 & 34,85 \\
\hline
\end{tabular}

Sumber: Badan Pusat Statistik Kabupaten Bengkalis (2020)

Menurut (Capello, (2009), hambatan istitusional (institutional barrier) bisa terjadi jika perbedaan dampak implementasi kebijakan yang berlaku disetiap daerah. Hal ini sesuai dengan kondisi kabupaten Bengkalis yang dominan pada sektor pertambangan dan penggalian. Undang-Undang Dasar Republik Indonesia (1945) pasal 33 yang menyebutkan bahwa "Bumi dan air dan kekayaan alam terkandung didalamnya dikuasai oleh Negara dan dipergunakan untuk sebesar-besar kemakmuran rakyat" yang langsung dikelola oleh pemerintah pusat, sementara pemerintah daerah hanya diberikan participating interest 10 persen yang diatur pada Undang-Undang Republik Indonesia Nomor 22 Tahun 2001 Tentang Minyak dan Gas Bumi tahun 2001. Berdasarkan aturan tersebut hasil pertambangan dari Kabupaten Bengkalis langsung dikelola oleh pemerintah pusat lalu dikembalikan sesuai dengan formula bagi hasil sektor pertambangan dan penggalian. Sehingga hasil pertambangan dan penggalian tidak seluruhnya dapat dikuasai oleh pemerintah kabupaten bengkalis untuk meningkatkan pertumbuhan ekonomi.

\section{Pertumbuhan Ekonomi Kabupaten Kuantan Singingi terhadap Kota Pekanbaru \\ Kabupaten Kuantan singingi} berpengaruh negatif dan signifikan terhadap pertumbuhan ekonomi Kota Pekanbaru, artinya jika pertumbuhan ekonomi kabupaten kuantan singingi meningkat maka menurunkan pertumbuhan ekonomi Kota Pekanbaru, begitu sebaliknya. Hal ini terjadi karena faktor lokasi geografis kabupaten kuansing yang tidak berbatasan langsung dengan Kota Pekanbaru.

Selain itu kabupaten kuansing memiliki PDRB yang tidak terlalu besar dibandingkan kabupaten lain. Sehingga dampak dari pertumbuhan ekonomi di kabupaten kuansing tidak memberikan efek yang dapat dirasakan bagi daerah lain khususnya Kota Pekanbaru. 


\section{Pertumbuhan Ekonomi Kabupaten Pelalawan terhadap Kota Pekanbaru}

Kabupaten pelalawan secara statistic berpengaruh positif dan signifikan terhadap PDRB Kota Pekanbaru. Sektor pertanian, kehutanan dan perikanan khususnya sub sektor perkebunan kelapa sawit dan industri pengolahan menjadi sektor unggulan di kabupaten tersebut. Industri pengolahan bidang kertas (pulp and paper) yang berada di kabupaten pelalawan memberikan efek besar terhadap kemajuan daerah melalui penyerapan tenaga kerja dalam maupun luar daerah sekitar sehingga dapat mendorong aktifitas ekonomi daerah.
Aktifitas ekonomi kabupaten pelalawan mampu memberikan efek positif terhadap PDRB Kota Pekanbaru sebagai daerah yang berbatasan langsung. Artinya dampak aglomerasi (agglomeration effect) dari industri pengolahan di Kabupaten pelalawan memberikan peluang bagi Kota Pekanbaru untuk menyediakan kebutuhan penunjang. Hal ini sesuai dengan pendapat Adisasmita, (2008) yang menyebutkan effect aglomerasi terjadi jika industri pendorong berhasil menarik kegiatan komplementer daerah lain untuk memperoleh kesempatan komulatif dengan biaya yang lebih rendah yang terkonsentrasi di kota-kota besar.

Tabel 8. Distribusi PDRB Kabupaten Pelalawan menurut Sektor tahun 2010-2019 (Persen)

\begin{tabular}{cccc}
\hline Tahun & $\begin{array}{c}\text { Pertanian, kehutanan, dan } \\
\text { Perikanan }\end{array}$ & Industri Pengolahan & Sektor lainnya \\
\hline $\mathbf{2 0 1 0}$ & 38,50 & 51,68 & 9,82 \\
\hline $\mathbf{2 0 1 1}$ & 38,04 & 51,50 & 10,46 \\
\hline $\mathbf{2 0 1 2}$ & 38,24 & 50,12 & 11,64 \\
\hline $\mathbf{2 0 1 3}$ & 38,75 & 48,56 & 12,69 \\
\hline $\mathbf{2 0 1 4}$ & 38,49 & 48,67 & 12,84 \\
\hline $\mathbf{2 0 1 5}$ & 39,00 & 48,78 & 12,22 \\
\hline $\mathbf{2 0 1 6}$ & 39,08 & 48,92 & 12,00 \\
\hline $\mathbf{2 0 1 7}$ & 39,18 & 48,91 & 11,91 \\
\hline $\mathbf{2 0 1 8}$ & 28,69 & 49,00 & 22,31 \\
\hline $\mathbf{2 0 1 9}$ & 38,80 & 49,01 & 12,19 \\
\hline
\end{tabular}

Sumber: Badan Pusat Statistik Kabupaten Pelalawan (2020)

Selain industri pengolahan kertas, sektor pertanian, kehutanan dan perikanan khususnya sub sektor perkebunan kelapa sawit memberikan simbangsih besar terhadap PDRB perkapita kabupaten pelalawan. Melalui peningkatan pendapatan penduduk kabupaten pelalawan dapat memberikan limpahan aktifitas ekonomi terhadap PDRB kota Pekanbaru pada sektor perdagangan. Karena akses dan kondisi geografis yang sangat memungkinkan penduduk pelalawan berbelanja dan mendorong perdagangan di Kota Pekanbaru.
Pertumbuhan Ekonomi Kabupaten Siak terhadap Kota Pekanbaru

PDRB Kabupaten Siak berpengaruh positif dan signifikan terhadap PDRB Kota Pekanbaru. Artinya peningkatan PDRB dikabupaten siak memberikan pengaruh terhadap peningkatan PDRB Kota Pekanbaru. Tidak jauh berbeda dengan kabupaten pelalawan, kabupaten siak juga menjadi kawasan industri pengolahan yaitu industri pulp and paper yang terkonsentrasi di kecamatan tualang.

Secara geografis Kabupaten Siak berbatasan langsung dengan Kota Pekanbaru, sehingga sangat 
memungkinkan tenaga kerja yang bekerja di industri tersebut untuk menetap dikota Pekanbaru. Selain itu, kondisi geografis dan akses jalan yang memadai juga mendorong penduduk Kabupaten Siak untuk berbelanja dan mendorong sektor perdagangan di Kota
Pekanbaru. Menurut Adisasmita, (2008) ekploitasi atau pengolahan sumberdaya alam dapat menjadi basis ekonomi untuk pembangunan wilayah/daerah yang memiliki struktur social ekonomi yang memungkinkan untuk menunjang perdagangan antar wilayah.

Tabel 9. Distribusi PDRB Kabupaten Siak menurut Sektor tahun 2010-2019 (Persen)

\begin{tabular}{ccccc}
\hline Tahun & $\begin{array}{c}\text { Pertanian, Kehutanan, dan } \\
\text { Perikanan }\end{array}$ & $\begin{array}{c}\text { Pertambangan dan } \\
\text { Penggalian }\end{array}$ & $\begin{array}{c}\text { Industri } \\
\text { Pengolahan }\end{array}$ & $\begin{array}{c}\text { Sektor } \\
\text { lainnya }\end{array}$ \\
\hline $\mathbf{2 0 1 0}$ & 18,65 & 41,47 & 33,62 & 6,26 \\
\hline $\mathbf{2 0 1 1}$ & 15,42 & 47,15 & 30,72 & 6,71 \\
\hline $\mathbf{2 0 1 2}$ & 14,05 & 53,18 & 26,42 & 6,35 \\
\hline $\mathbf{2 0 1 3}$ & 14,15 & 53,18 & 26,42 & 6,25 \\
\hline $\mathbf{2 0 1 4}$ & 15,04 & 48,01 & 29,40 & 7,55 \\
\hline $\mathbf{2 0 1 5}$ & 17,27 & 38,89 & 34,82 & 9,02 \\
\hline $\mathbf{2 0 1 6}$ & 18,46 & 36,50 & 35,38 & 9,66 \\
\hline $\mathbf{2 0 1 7}$ & 19,67 & 34,45 & 35,74 & 10,14 \\
\hline $\mathbf{2 0 1 8}$ & 18,87 & 36,44 & 34,56 & 10,13 \\
\hline $\mathbf{2 0 1 9}$ & 20,10 & 31,83 & 36,78 & 11,29 \\
\hline
\end{tabular}

Sumber: Badan Pusat Statistik Kabupaten Siak (2020)

Selain industri pengolahan pulp and paper, kabupaten siak juga memiliki sektor pertambangan dan penggalian serta sektor pertanian kehutanan dan perikanan khususnya sub sektor kepala sawit yang memberikan sumbangsih besar tehadap PDRB Kabupaten siak.

\section{Pertumbuhan Ekonomi Kabupaten Kampar terhadap Kota Pekanbaru}

Kabupaten Kampar secara statistik berpengaruh positif dan signifikan jika alpha 10 persen. Artinya jika terjadi peningkatan PDRB di Kabupaten Kampar akan memberikan efek positif pada PDRB di Kota Pekanbaru. Secara geografis kabupaten terluas di provinsi riau ini berbatasan langsung dengan Kota Pekanbaru dan memiliki akses yang baik. Kabupaten Kampar juga menjadi akses utama menuju beberapa kabupaten di provinsi riau dan menuju provinsi Sumatera Barat

Tabel 10 Distribusi PDRB Kabupaten Kampar menurut Sektor tahun 2010-2019 (Persen)

\begin{tabular}{ccccc}
\hline Tahun & $\begin{array}{c}\text { Pertanian, Kehutanan, dan } \\
\text { Perikanan }\end{array}$ & $\begin{array}{c}\text { Pertambangan dan } \\
\text { Penggalian }\end{array}$ & $\begin{array}{c}\text { Industri } \\
\text { Pengolahan }\end{array}$ & $\begin{array}{c}\text { Sektor } \\
\text { lainnya }\end{array}$ \\
\hline $\mathbf{2 0 1 0}$ & 30,02 & 32,47 & 24,45 & 13,06 \\
\hline $\mathbf{2 0 1 1}$ & 25,97 & 40,30 & 21,78 & 11,95 \\
\hline $\mathbf{2 0 1 2}$ & 24,05 & 42,72 & 21,03 & 12,20 \\
\hline $\mathbf{2 0 1 3}$ & 22,17 & 45,56 & 20,36 & 11,91 \\
\hline $\mathbf{2 0 1 4}$ & 22,30 & 45,86 & 19,65 & 12,19 \\
\hline $\mathbf{2 0 1 5}$ & 24,87 & 39,21 & 21,97 & 13,95 \\
\hline $\mathbf{2 0 1 6}$ & 26,12 & 36,94 & 22,35 & 14,59 \\
\hline $\mathbf{2 0 1 7}$ & 27,37 & 34,48 & 23,02 & 15,13 \\
\hline $\mathbf{2 0 1 8}$ & 26,31 & 36,68 & 22,03 & 14,98 \\
\hline $\mathbf{2 0 1 9}$ & 27,82 & 32,37 & 23,54 & 16,27 \\
\hline
\end{tabular}

Sumber: Badan Pusat Statatistik Kabupaten Kampar (2020) 
PDRB Kabupaten kampar didorong oleh sektor potensial yaitu pertanian, kehutanan dan perikanan dan pertambangan dan penggalian serta industri pengolahan. Dengan adanya sumberdaya alam yang cukup besar menjadikan kabupaten Kampar sebagai salah satu kabupaten yang memiliki perkebunan kelapa sawit terluas diprovinsi Riau. Melalui sektor-sektor unggulan kabupaten Kampar dapat memberikan limpahan aktifitas ekonomi bagi Kota Pekanbaru. Berikut sektor yang paling berpengaruh terhadap PDRB Kabupaten Kampar.

Selain meningkatkan PDRB secara agregat, potensi sumberdaya alam juga meningkatkan pedapatan perkapita bagi penduduk. Peningkatan pendapatan akan meningkatkan konsumsi penduduk, sehingga factor produksi yang tidak tersedia dikabupaten tersebut harus disediakan daerah lainnya seperti kota Pekanbaru. Hal ini menunjukkan bahwa limpahan aktifitas ekonomi baik dalam bentuk mobilitas barang, tenaga kerja dan modal maupun eksternalitas spasial akan mempengaruhi aktifitas ekonomi dalam suatu wilayah atau daerah (Suparta, 2009).

\section{PENUTUP \\ Kesimpulan}

Kondisi geografis dan akses yang baik akan sangat berpengaruh terhadap limpahan aktifitas perekonomian dari suatu daerah terhadap daerah lainnya, hal ini ditunjukkan dengan pengaruh positif PDRB kabupaten siak, PDRB pelalawan dan PDRB Kabupaten Kampar terhadap PDRB kota Pekanbaru yang berbatasan langsung. Dorongan sektor yang menjadi prioritas juga memiliki peran penting, misalnya sektor industri pengolahan dan sub sektor perkebunan kelapa sawit dapat mendorong peningkatan pendapatan perkapita yang menyebabkan peningkatan konsumsi penduduk. Sehingga limpahan peningkatan aktifitas ekonomi di kabupaten siak, Kampar, dan pelalawan akan terus dirasakan oleh kota Pekanbaru.

Pengembangan potensi ekonomi di daerah-daerah yang berbatasan dengan Kota Pekanbaru perlu terus ditingkatkan agar peningkatan PDRB dapat dirasakan lebih besar lagi baik bagi daerah itu sendiri maupun daerah lainnya melalui limpahan pertumbuhan ekonomi. Keterbatasan penelitian ini yaitu masih terdapat beberapa variable yang harus digunakan untuk melakukan kajian yang lebih mendalam, agar hasil yang diperoleh lebih banyak sudut pandang dan perspektif.

\section{Saran}

Saran dari kajian ini yaitu pengembangan potensi ekonomi di daerah-daerah yang berbatasan dengan Kota Pekanbaru perlu terus ditingkatkan agar peningkatan PDRB dapat dirasakan lebih besar lagi baik bagi daerah itu sendiri maupun daerah lainnya melalui limpahan pertumbuhan ekonomi.

\section{ACKNOWLEDGEMENT}

Penelitian ini dibiayai oleh direktorat Riset dan Pengabdian Masyarakat. Direktorat Jendral Penguatan Riset Dan Pengembangan. Kementrian Riset, Teknologi, dan Pendidikan Tinggi Sesuai dengan Kontrak Penelitian Nomor: 50/KONTRAK/LPPM/4-2020.

\section{DAFTAR PUSTAKA}

Adisasmita, R. (2008). Pengembangan Wilayah (Konsep dan Teori) (Pertama). Graha Ilmu.

Aghion, P., \& Jaravel, X. (2015). Knowledge spillovers, innovation and growth. Economic Journal, 125(583), 533-573. https://doi.org/10.1111/ecoj.1219 
Aiyubbi, D. El, \& Wijayanti, D. (2014). Pengaruh RegionalSpillover Terhadap PDRB Daerah Istimewa Yogyakarta Tahun 1996-2010. Aplikasi Bisnis, 15(9), 1777-1798.

Anata Salam, S., \& Prishardoyo, B. (2018). Pengaruh Human Capital Spillover Effects terhadap Produktivitas Industri Pengolahan Kawasan Kedungsepur. Economics Development Analysis Journal, 5(2), 226-234. https://doi.org/10.15294/edaj.v5i 2.22036

Arsyad, L. (2004). Pengantar Perencanaan dan Pembangunan Ekonomi Daerah. BPFE Universitas Gajah Mada.

Capello, R. (2009). Spatial spillovers and regional growth: A cognitive approach. European Planning Studies, 17(5), 639-658. https://doi.org/10.1080/09654310 902778045

Carlino, G. A. (2001). Knowledge Spillovers: Cities' Role in the New Economy. Business Review. https://doi.org/10.7551/mitpress/ 2613.003.0007

Ghozali, I., \& Ratmono, D. (2017). Analisis multivariat dan ekonometrika. badan penerbit universitas diponegoro.

Gujarati, D. N. (2003). Basic Econometrics (4th ed.). McGrawHill.

Harahap, B. A., Bary, P., Nurliana, L., \& Satyanugroho, R. (2015). Dampak Spillover Shock Eksternal Pada Perekonomian Indonesia: Pendekatan Global Var. Working Paper Bank Indonesia, June.
Hirschman, A. (1984). A Dissenter's Conffesion: "The Strategy of Economic Development" Revisited. Pioneers in Development, 1(1), 85-111. http://www.rrojasdatabank.info/p ioneers4.pdf

Jaffe, A. B., Trajtenberg, M., \& Fogarty, M. S. (2000). Knowledge Spillovers and Patent Citations: Evidence from a Survey of Inventors. American Economic Review, 90(2), 215-218. https://doi.org/10.1257/aer.90.2.2 15

Laksono, H., Rustiadi, E., \& Siregar, H. (2018). Spillover Spasial Negatif Pertumbuhan Ekonomi Antar Kabupaten/Kota di Provinsi Jawa Timur. Tataloka, 20(3), 266. https://doi.org/10.14710/tataloka. 20.3.266-277

Li, F., \& Li, G. (2018). Agglomeration and spatial spillover effects of regional economic growth in China. Sustainability (Switzerland), 10(12), 1-13. https://doi.org/10.3390/su101246 95

Luo, X. (2005). Growth Spillover Effects and Regional Development Patterns: The Case of Chinese Provinces. World Bank Policy Research Working Paper, 1-29.

Musa Ahmed, E. (2012). Are trade spillover effects on East Asian economic growth productivity driven? World Journal of Entrepreneurship, Management and Sustainable Development, 8(4), 246-259. https://doi.org/10.1108/20425961 211276624 
Seif, A. M., Panahi, H., \& Razi, D. H. (2017). Regional Economic Growth and Spatial Spillover Effects in MENA Area. Iran. Econ. Rev, 21(4), 765-787.

Suparta, I. W. (2009). Spillover Effect Perekonomian Provinsi Dki Jakarta dan sumatera selatan terhadap pertumbuhan ekonomi provinsi lampung. Jurnal Ekonomi Pembangunan, 10(1), 32-48.

Wibisono, P., \& Kuncoro, M. (2015). Efek Limpahan Pertumbuhan Antar-Kabupaten /Kota di Provinsi Jawa Timur Tahun 2001 - 2013. Jurnal Ekonomi Dan Pembangunan Indonesia, 16(1), 31-46.

https://doi.org/http://dx.doi.org/1 0.21002/jepi.v16i1.584

Widarjono, A. (2018). Ekonometrika pengantar dan aplikasinya disertai panduan eviews (5th ed.). UPP STIM YKPN. 